\title{
Photovoltage formation across Si p-n junction exposed to laser radiation
}

\author{
Steponas AŠmONTAS ${ }^{1, *}$, JONAS GRAdAUSKaS ${ }^{1}$, AlgIRdAS SUŽIEdĖlis ${ }^{1}$, Aldis ŠILĖNAS ${ }^{1}$, \\ EDMUNDAS ŠIRMULIS ${ }^{1}$, VITAS ŠVEDAS ${ }^{1}$, VIKTORAS VAIČIKAUSKAS ${ }^{1}$, VYTAUTAS VAIČIŪNAS ${ }^{1}$, \\ OVIDIJUS ŽALYS ${ }^{1}$, Vitaliy KOSTYLYOV ${ }^{2}$ \\ ${ }^{1}$ Center for Physical Sciences and Technology, Vilnius, Lithuania \\ ${ }^{2}$ V. Lashkaryov Institute of Semiconductor Physics of National Academy of Sciences of Ukraine, Kyiv, Ukraine
}

\begin{abstract}
Photovoltage formation across Si p-n junction exposed to laser radiation is experimentally investigated. Illumination of the junction with $1.06 \mu \mathrm{m}$ wavelength laser radiation leads to formation of classical photovoltage $\mathrm{U}_{\mathrm{ph}}$ due to intense electronhole pair generation. When the photon energy is lower than the semiconductor forbidden energy gap, the photovoltage $U$ is found to consist of two components, $U=U_{f}+U_{p h}$. The first $U_{f}$ is a fast one having polarity of thermoelectromotive force of hot carriers. The second $U_{p h}$ is classical photovoltage with polarity opposite to $U_{f}$. It is found that $U_{f}$ is linearly dependent on laser intensity. The classical photovoltage is established to decrease with the rise of radiation wavelength due to decrease in two-photon absorption coefficient with wavelength. Predominance of each separate component in the formation of the net photovoltage depends on both laser wavelength and intensity.
\end{abstract}

Keywords: silicon; laser radiation; p-n junction; solar cell; hot carriers

\section{Introduction}

Electric energy generated by solar cells (SC) is a most promising and environmentally friendly energy source. However, the SC generated electricity is currently significantly more expensive than the electricity acquired by traditional methods due to high price of solar cells. At present time, about $80 \%$ of worldwide SC are made from silicon. The efficiency of a one-junction silicon solar cell produced in a scientific laboratory reaches $25.6 \%$ and is close to the theoretical limit of $33.3 \%$ [1]. Solar cell efficiency is limited by the efficient use of only photons having energy close to the forbidden energy gap. Photons with higher energies create electron-hole pairs, but the excess energy is transmitted to the carriers which then become hot carriers. In an ideal single junction solar cell $55 \%$ of incident solar radiation is lost due to the thermalization of hot carriers with lattice [2]. Ross et al. [3] proposed the idea of hot carrier solar energy convertors in which photoexcited carriers should be

*E-mail: steponas.asmontas@ftmc.lt extracted over a narrow range of energies at a rate faster than they lose energy to the lattice. Theoretical efficiency of such device can be sufficiently high, up to $66 \%$. Lately, large number of theoretical and experimental works have been carried out in developing hot carrier solar cells [4-6] as it was theoretically shown that maximum efficiency of such devices can reach $85 \%$ [4]. However, no hot carrier solar cell valuable for practical applications has been built yet. Nevertheless, hot carriers must be taken into account during the study of photovoltage formation across a $\mathrm{p}-\mathrm{n}$ junction under the sunlight illumination.

In this paper, we present the results of experimental investigation of hot carriers influence on the photoresponse formation across $\mathrm{Si}$ p-n junction illuminated by laser radiation of different wavelength.

\section{Experimental}

The investigated $p-n$ junction was produced by chemical vapor deposition of epitaxial p-type $\mathrm{Si}$ on n-type $\mathrm{Si}$ substrate. Electron density was 
$7 \times 10^{15} \mathrm{~cm}^{-3}$, and respective hole density was $5 \times 10^{16} \mathrm{~cm}^{-3}$. Ohmic contact to $\mathrm{p}$-Si was formed by boron diffusion into a thin $\mathrm{p}^{+}$-layer at $950{ }^{\circ} \mathrm{C}$ temperature giving hole density of $8 \times 10^{19} \mathrm{~cm}^{-3}$, and subsequent thermal deposition of aluminium at a temperature of $300{ }^{\circ} \mathrm{C}$ and annealig at $560{ }^{\circ} \mathrm{C}$ in Ar atmosphere for 1 minute. The p-n junction was illuminated from the epitaxial layer side through the square window etched in the $\mathrm{p}^{+}$-layer (Fig. 1). In the experiments, the Nd:YAG laser with $1.06 \mu \mathrm{m}$ wavelength and $25 \mathrm{~ns}$ pulse duration was used. $\mathrm{LiNbO}_{3}$ nonlinear crystal was used to shift the radiation wavelength. To increase the excitation intensity, the laser beam was focused on the sample surface, and thus maximum pulse power intensity was about $1 \mathrm{MW} / \mathrm{cm}^{2}$. Temporal behavior of the photovoltage and laser pulse in the nanosecond time scale was recorded by digital storage oscilloscope Instek GDS-2202. All the measurements were carried out at room temperature.

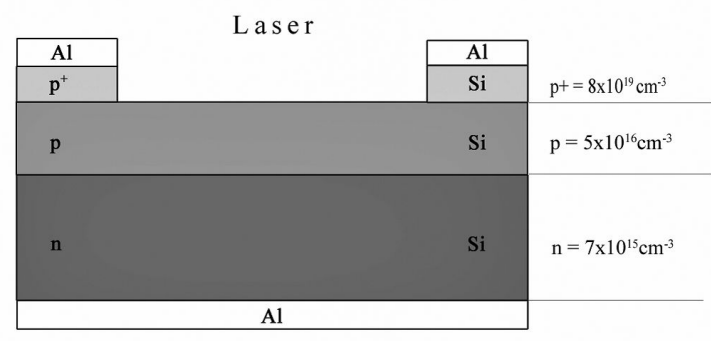

Fig. 1. Si sample structure (not to scale).

\section{Results and discussion}

The spectral dependence of short circuit photocurrent is depicted in Fig. 2. It is seen that the photocurrent has maximum at $\lambda=940 \mathrm{~nm}$, and a cutoff wavelength is $1180 \mathrm{~nm}$ for the case of low light intensity. Illumination of $\mathrm{Si} \mathrm{p}$-n junction with $1.06 \mu \mathrm{m}$ laser radiation leads to intense electron-hole pair generation. In this case, the classical photovoltage $U_{\mathrm{ph}}$ can be observed across the junction. The situation changes essentially with the wavelength increase.

Temporal profile of the photovoltage across $\mathrm{Si}$ p-n junction induced by $1.489 \mu \mathrm{m}$ laser radiation

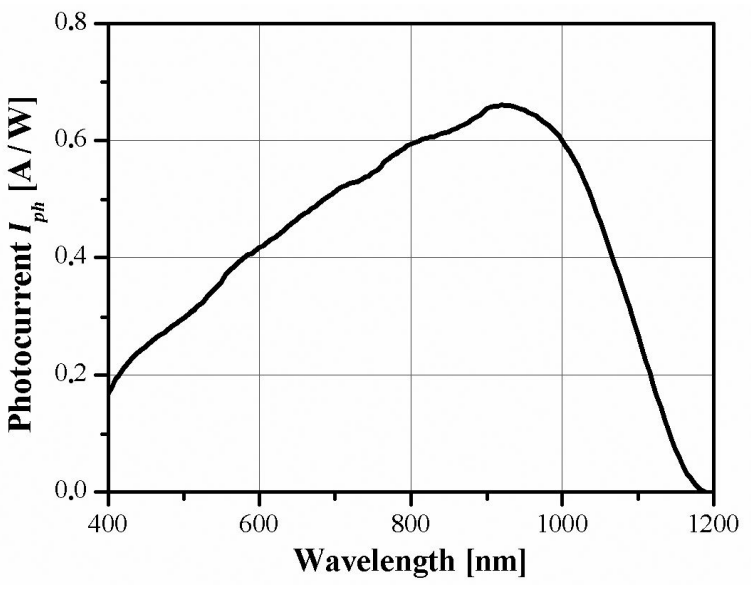

Fig. 2. Spectral dependence of short-circuit photocurrent through Si p-n junction at low light intensities.

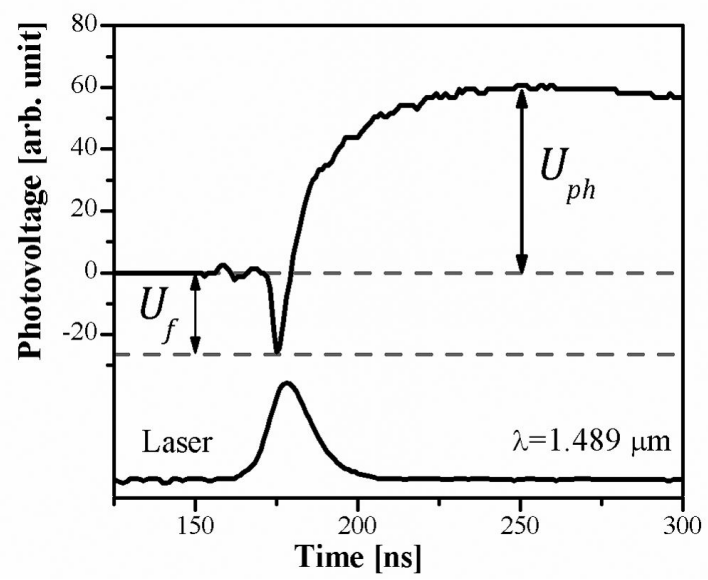

Fig. 3. Oscilloscope traces of laser pulse (bottom) and photovoltage (top) consisting of two components.

is presented in Fig. 3. The observed photovoltage U now consists of two components:

$$
U=U_{f}+U_{p h}
$$

where $U_{f}$ is the fast component with polarity corresponding to that of thermoelectromotive force of hot carriers [7], and $\mathrm{U}_{\mathrm{ph}}$ is the slow component of opposite polarity, which is classical photovoltage caused by electron-hole pair generation. It is necessary to note that, similar to the GaAs case [8], the thermoelectromotive force of hot carriers across $\mathrm{Si}$ p-n junction is a dominant component of the photovoltage at low excitation level, and at higher laser 
intensities $\mathrm{U}_{\mathrm{ph}}$ prevails in the formation of the photovoltage. Moreover, investigations revealed that $\mathrm{U}_{\mathrm{ph}}$ increases with the intensity of laser radiation following the square law (see Fig. 4). This fact indicates that the electron-hole pair generation is determined by the two-photon absorption since the single laser photon energy is lower than the forbidden energy gap of silicon.

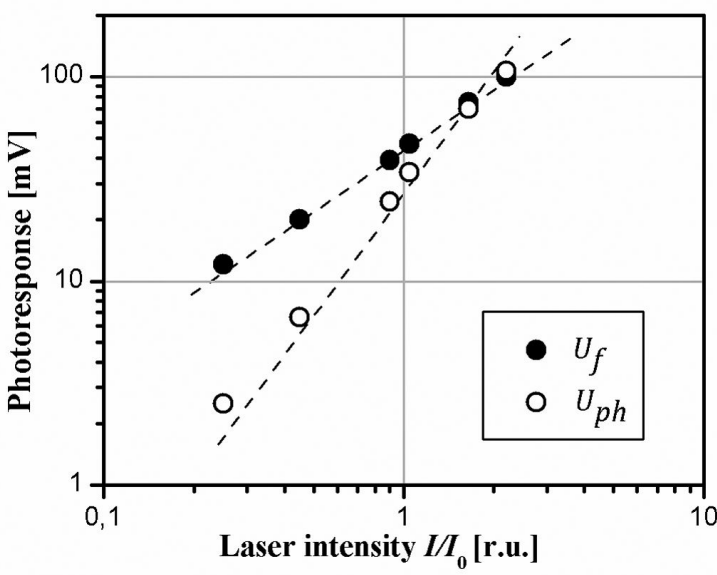

Fig. 4. The dependence of the classical photovoltage $\mathrm{U}_{\mathrm{ph}}$ and the hot carrier thermoelectromotive force $\mathrm{U}_{\mathrm{f}}$ across $\mathrm{Si}$ p-n junction on $1.489 \mu \mathrm{m}$ laser intensity.

In turn, $\mathrm{U}_{\mathrm{f}}$ is linearly dependent on the laser intensity. Such linear dependence is an inherent feature of the hot carrier thermoelectromotive force [7]. Thus, the formation of hot carrier thermoelectromotive force reduces the efficiency of a solar cell as far as its polarity is opposite to that of the classical photovoltage.

The dependencies $\mathrm{U}_{\mathrm{f}}$ and $\mathrm{U}_{\mathrm{ph}}$ on laser radiation wavelength are depicted in Fig. 5. It is seen that $\mathrm{U}_{\mathrm{ph}}$ decreases as the wavelength gets longer, and at $\lambda>2.5 \mu \mathrm{m}$, the slow component of the photovoltage vanishes. This behavior is associated with the decrease in two-photon absorption coefficient with wavelength [9]: at $\lambda>2.5 \mu \mathrm{m}$ the energy of two photons is lower than the forbidden energy gap of $\mathrm{Si}$, and no generation of electron-hole pairs is observed.

The hot carrier thermoelectromotive force $\mathrm{U}_{\mathrm{f}}$ also drops down when $\lambda$ increases from $1.489 \mu \mathrm{m}$

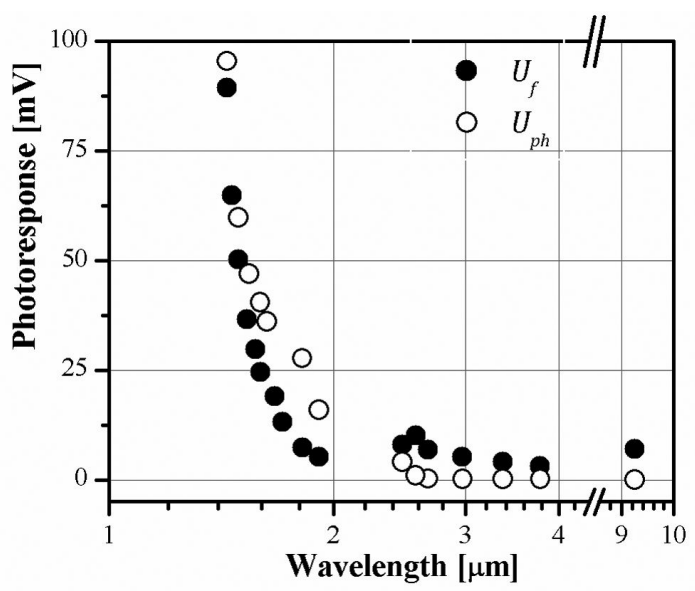

Fig. 5. The spectral dependence of the hot carrier thermoelectromotive force $\mathrm{U}_{\mathrm{f}}$ and the classical photovoltage $\mathrm{U}_{\mathrm{ph}}$ under intense laser illumination.

to $1.9 \mu \mathrm{m}$. However, in contrast to $\mathrm{U}_{\mathrm{ph}}, \mathrm{U}_{\mathrm{f}}$ does not tend to zero but even slightly increases at longer laser wavelengths, $\lambda>1.9 \mu \mathrm{m}$. In this spectral range, the hot carrier thermoelectromotive force is determined by the optical absorption coefficients of free electrons and free holes $[10,11]$.

\section{Summary}

Peculiarities of photovoltage formation across Si p-n junction under illumination of laser radiation was investigated. When the laser radiation wavelength is longer than semiconductor cutoff wavelength, the observed photoresponse consists of two components. The fast component is caused by the laser-induced carrier heating, and the slow one is a classical photovoltage caused by electron-hole pair generation. The classical photovoltage was found to increase with laser intensity according to the square law. This fact indicates that the carrier generation is determined by two-photon absorption. At low excitation levels, the photoresponse is mainly dominated by the thermoelectromotive force of hot carriers, and at high intensities, the generation of electron-hole pairs prevails. As a result, the carrier heating reduces the efficiency of a solar cell as far as the polarity of the thermoelectromotive force of hot carriers is opposite to that of the classical photovoltage. 


\section{Acknowledgements}

The authors are grateful to Angelè Steikūnienè and Gytis Steikūnas for their kind technical assistance in sample preparation. This investigation has been carried out under the partial financial support of the Research Council of Lithuania (Grant No. TAP-LU-5-2016).

\section{References}

[1] Polman A., Knight M., Garnett E.C., Ehler B., SINKE W.C., Science, 352 (2016), aad4424.

[2] Hirst L.C., Ekins-Daukes N.J., Prog. Photovolt. Res. Appl., 19 (2011), 286.

[3] Ross R.T., Nozik A.J., J. Appl. Phys., 53 (1982), 3813.

[4] Kirk A.P., Fischetti M.V., Phys. Rev. B, 86 (2012), 165206-1.

[5] Hirst L.C., Fujil H., Wang Y., Sigiyama M., Ekins-Daukes N.J., IEEE J. Photovolt., 4 (2014), 244.
[6] Rodiere J., Lombez L., Le Corre A., Durand O., Guillemoles J.F., Appl. Phys. Lett., 106 (2015), 183901.

[7] Gradauskas J., ŠIrmulis E., Ašmontas S., SuŽIEdélis A., Dashevsky Z., Kasiyan V., Acta Phys. Pol. A, 119 (2011), 273.

[8] AŠmontas S., Gradauskas J., SuŽIEdĖlis A., ŠILĖNAS A., ŠIRMULIS E., VAIČIKAUSKAS V., VAIČIŪnas V., Žalys O., FEDOREnko L., BULAT L., Opt. Quant. Electron., 48 (2016), 448.

[9] Bristow A.D., Rotenberg N., Driel VAn H.M., Appl. Phys. Lett., 90 (2007), 191104.

[10] Spitzer W., FAn M.Y., Phys. Rev., 108 (1957), 268.

[11] Dargys A., Kundrotas J., Handbook of physical properties of Ge, Si, GaAs and InP, Science and Encyclopedia Publishers, Vilnius, 1994.

Received 2017-07-14

Accepted 2017-12-04 